\title{
Adsorption of p-cresol on novel diatomite/carbon composites
}

\author{
H. Hadjar ${ }^{1,2}$, B. Hamdi ${ }^{2}$, C.O. Ania ${ }^{3 *}$ \\ ${ }^{1}$ C.R.A.P, BP248, Alger RP 16004Alger, Algerie, \\ ${ }^{2}$ LPCMAE USTHB - Faculté de Chimie BP 32, Bab Ezzouar 16111 Alger, Algérie \\ ${ }^{3}$ Instituto Nacional del Carbon (INCAR, CSIC) PO 73, 33080, Oviedo, Spain
}

\begin{abstract}
Hybrid inorganic/organic adsorbents were synthesized using mixtures of diatomite and carbon charcoal as precursors, and explored for the removal of p-cresol from aqueous solution. The carbon/diatomite composites displayed a bimodal and interconnected porous structure which was partially inherited from both precursors. They display moderate surface areas (between $100-400 \mathrm{~m}^{2} \mathrm{~g}^{-1}$ ) due to their large inorganic content (between 70-90 wt.\%), since the diatomite is a non porous material. Compared to activated carbons with a more developed porosity, p-cresol adsorption on the prepared carbon/diatomite composites was much faster, showing adsorption capacities similar to those of conventional adsorbents over a wide $\mathrm{pH}$ range. These results show a good affinity of p-cresol molecules towards the hybrid inorganic/organic composites, and demonstrate the suitability of these novel materials for the removal of aromatic (polar) molecules, despite their dominant inorganic character.
\end{abstract}

Keywords: adsorption; p-cresol; diatomite; carbon composite

*- corresponding author, E-mail: conchi.ania@incar.csic.es (CO Ania); Tel. +34 985 118846; Fax +34985297662 


\section{Introduction}

A direct consequence of the fast development of industrial activities is that the amount and variety of chemical wastes thrown into water resources has rapidly increased. Very often small amounts of synthetic organic compounds (including phenol and its derivatives, pesticides, aliphatic and aromatic hydrocarbons, dyes and surfactants among most representatives) are detected in water streams $[1,2]$. These compounds are known to possess high toxicity and low biodegradability, for which their occurrence in wastewater has become an important environmental issue.

Adsorption technology is a widely used technique for water treatment, and carbonaceous adsorbents (particularly activated carbons) are among the most common and effective ones due to their adequate porous and chemical features [3-6]. Although the market for activated carbons in wastewater remediation is large and growing, the large scale implementation of this technology is somehow limited due to the drawbacks associated to the poor regeneration efficiency and high costs of the activated carbons.

Our recent works have focused on the synthesis of carbon/diatomite composites with a hierarchical porous structure [7]. Separately, both precursors are widely used as adsorbents in different applications; the diatomite is known to show good adsorbent properties towards inorganic pollutants, whereas the carbon matrix -being essentially microporous and hydrophobicshows a good adsorption properties towards non-polar molecules. Since the adsorptive properties of both materials are complementary, a mixture of both could be of high interest for some specific applications such as separation and purification purposes. Indeed, the beneficial effect of mixtures of diatomite with a carbonaceous matrix -choosing the right mass ratio followed by an adequate heat treatment- on the chemical and porous features of the obtained diatomite/carbon composites for an improved adsorption of toxic ions (i.e., lead) has been discussed in previous studies $[7,8]$. The objective of this work was to investigate the application of novel carbon/diatomite composites prepared from an algerian diatomite and a carbon precursor in the removal of polar aromatic compounds (i.e., p-cresol) from diluted aqueous solutions. The adsorption performance of the hybrid composites has been compared to that of activated carbons with a more developed porosity. In this sense, p-cresol (along with phenol itself) is one of most abundant phenolic compound frequently found in industrial wastewater. It is widely used in many chemical industries, namely petrochemical, oil refinery, chemical and glass fiber resins manufacturing, ceramic and steel plants, disinfectant manufacturing, or metal refining. In recognition of its toxicity (likely human carcinogen) and high mobility in the environment, the Environmental 
Protection Agency (EPA) and the European Environmental Agency (EEA) have included this compound in the lists of priority pollutants to be monitored in industrial effluents [10-12].

\section{Experimental}

\subsection{Materials}

The synthetic procedure followed for the preparation of the carbon/diatomite composites has been reported elsewhere [7]. Briefly, different amounts of an Algerian diatomite (obtained from Sig deposit located in the westward of Algeria, Kieselguhr) and a carbon charcoal (wood-derived) were mixed and submitted to a thermal treatment under nitrogen atmosphere $\left(50 \mathrm{ml} \mathrm{min}^{-1}\right)$ up to $850^{\circ} \mathrm{C}$ (heating rate $5^{\circ} \mathrm{C} \mathrm{min}^{-1}$ ) for 1 hour. Afterwards, a chemical treatment with hydrochloric acid (0.5 N, Sigma Aldrich, Spain) and subsequent washing with distilled water were carried out. The samples were then dried overnight at $110^{\circ} \mathrm{C}$ and preserved in desiccator until their use. Two composites, using carbon:diatomite ratios 10:90 and 30:70 (weight basis) were prepared; the samples will be labeled as $\mathrm{KC} 1$ and $\mathrm{KC} 3$, respectively.

\subsection{Characterization of porous texture}

Textural characterization was carried out by measuring the $\mathrm{N}_{2}$ adsorption isotherms at $-196{ }^{\circ} \mathrm{C}$ in an automatic apparatus (Micrometrics ASAP 2010 M, USA). Before the experiments, the samples were outgassed under primary vacuum at $120^{\circ} \mathrm{C}$ overnight (VacPrep 061, Micrometrics, USA). The isotherms were used to calculate specific surface area $S_{\mathrm{BET}}$, total pore volume $\mathrm{V}_{\mathrm{T}}$, and pore size distribution using the DFT model and assuming slit-shape pore geometry. Ultra high purity nitrogen (i.e., $99.9999 \%$ ) was purchased from Carburos Metalicos (Spain). The morphology of the samples was characterized by scanning electron microscopy (SEM) using a Philips XL30 apparatus (Philips, USA). Before the analysis, the samples were dispersed on a graphite adhesive tab placed on an aluminum stub and metallized with gold. The point of zero charge $\left(\mathrm{pH}_{\mathrm{PZC}}\right)$ was determined by the mass titration method as indicated elsewhere [13] (using a pHmeter Basic 20+, Crison, Spain).

\subsection{Adsorption measurements}

p-cresol (4-methylphenol) was supplied by Sigma-Aldrich, Spain (purity 98\%). Unbuffered solutions were prepared using ultra-pure water (Milli-Q Millipore $18.2 \mathrm{M} \Omega \mathrm{cm}^{-1}$ conductivity) and $\mathrm{pH}$ value was around 6.2. All the adsorption measurements were carried out at room temperature in a stirred batch system thermostatically controlled with an external circulating bath. Before these experiments, kinetics studies were performed to determine the equilibration time of 
the systems. Different amounts of adsorbents (from 5 to $40 \mathrm{mg}$ ) were weighted and added to glass vials containing $30 \mathrm{~mL}$ of p-cresol solution of varied initial concentrations (between 20-120 ppm). The covered vials were placed under continuous stirring at controlled temperature for 24 hours. For the kinetic studies aliquots were collected between $5 \mathrm{~min}$ and $24 \mathrm{~h}$. After equilibration, the residual concentration of $\mathrm{p}$-cresol remaining in the solution was determined using a UV-vis spectrophotometer (Shimadzu UV-2501, Japan) at $277 \mathrm{~nm}$. A blank was checked for every experiment to verify that adsorbate volatilization (or adsorption on the walls) does not occur; all the adsorption measurements were done in triplicate. The amount adsorbed was determined according to Eq. (1)

$q_{t}=\frac{\left(C_{0}-C_{t}\right)}{W} V$

where $q_{\mathrm{t}}$ is the amount $\left(\mathrm{mg} \mathrm{g}^{-1}\right)$ adsorbed at time $t, C_{0}$ is the initial concentration (ppm), $C_{\mathrm{t}}$ is the concentration at time $t(\mathrm{ppm}), V$ is the volume (1) of the adsorbate solution and $W$ is the weight $(\mathrm{g})$ of the adsorbent.

The effect of solution $\mathrm{pH}$ on the retention of p-cresol on the studied adsorbents was investigated by adding $0.1 \mathrm{M} \mathrm{NaOH}$ or $\mathrm{HCl}$ (for $\mathrm{pH}$ adjustment) to the stock solution containing the aromatic compound.

\section{Results and discussion}

\subsection{Characterization of the composites}

A detailed analysis on the effect of the different synthetic parameters during the preparation of the composites with varied carbon to diatomite ratio has been previously discussed [7]. Here we merely report the main textural parameters of the composites used in the removal of p-cresol from solution for data interpretation (Table 1).

The nitrogen adsorption isotherms of the selected carbon/diatomite composites are shown in Figure 1, along with those corresponding to selected commercially available activated carbons, which have been included for comparison purposes. It can be observed that the diatomite/carbon composites display hybrid I/IV type isotherms according to the BDDT classification [14] indicating a bimodal micro/mesoporous pore structure, partially inherited from both precursors [7]. In both samples the low pressure region displays a sharp knee that indicates the presence of micropores. The existence of a large hysteresis loop and capillary condensation step at relative pressures above 0.5 also confirms that $\mathrm{KC} 1$ and $\mathrm{KC} 3$ are mesoporous systems. The shape of the hysteresis loop (H4) is associated with capillary condensation in slit-shaped mesopores [15]. 
Comparatively, it seems that the microporous character of the composites increases with the carbon content, even if diatomite (macroporous material) is the dominant component in these materials (mass fraction beyond $50 \mathrm{wt} . \%$ in both cases). This was corroborated by the large apparent surface area $\left(\mathrm{S}_{\mathrm{BET}}\right)$ of sample $\mathrm{KC}$, along with its high micropore volume obtained from the DFT method (Table 1).

The diatomite/carbon composites exhibit specific BET surface areas which are tens of times greater than those of raw diatomite (ca., $8 \mathrm{~m}^{2} \mathrm{~g}^{-1}$ ) and slightly higher that that of the carbon charcoal (ca., $120 \mathrm{~m}^{2} \mathrm{~g}^{-1}$ ) [7]. It is interesting to remark that sample $\mathrm{KC} 3$ displays a surface area similar to that of hierarchical porous carbons prepared by nanocasting procedures using diatomite as scaffold and furfuryl alcohol as carbon precursor [9], despite the inorganic template is preserved in the composites herein described (as opposed to template procedures).

SEM micrographs (Figure 2) show that the open macroporous network characteristic of the diatomite is inherited by composites $\mathrm{KC} 1$ and $\mathrm{KC} 3$. The diatomaceous wall structure appears slightly covered by the carbon layer incorporated in the synthesis, although its distribution is not uniform. This is more evident in the sample with the lowest carbon loading (sample KC1). Nevertheless, no pore plugging effects were observed as a consequence of the incorporation of the carbon layer, since the macropores characteristics of the diatomite remained unblocked in both composites. This was somewhat expected considering that the carbon loading of the composites (ca., 10 and $30 \mathrm{wt} . \%$ ) are below the saturation value needed to cover completely the diatomite surface (ca. $40 \mathrm{wt} . \%$ ) evaluated in previous studies [7].

According to gas adsorption data and SEM images it can be observed that, despite the low carbon loading, the diatomite/carbon composites possess an ordered structure consisting of micropores (provided by the carbon charcoal) interconnected by the ordered macroporous network (provided by the diatomite). The reason for this is that, as opposed to nanocasting synthetic routes reported in the literature for the preparation of hierarchically porous carbons where the inorganic scaffold is removed [9], our goal was to investigate the adsorption properties of the hybrid diatomite/carbon composites and thus the diatomaceous matrix was preserved. The macropore structure in the carbon/diatomite composites is expected to contribute to an enhancement in the mass transport of the pollutant during the adsorption process.

\subsection{Kinetics of adsorption from solution}

Figure 3 shows the evolution of p-cresol concentration with time for the diatomite/carbon composites, along with data corresponding to selected activated carbons used as reference materials. The concentration decay curves show that the removal of p-cresol steadily increased 
with time and that it takes around 6-8 hours to reach equilibrium for all the samples (below $24 \mathrm{~h}$ in any case), regardless of their nature. The same trend was obtained when the adsorbent dosage was varied (see data corresponding to $\mathrm{KCl}$ in Figure $3 \mathrm{~B}$ as an example), while keeping constant the initial concentration $(100 \mathrm{ppm})$ and volume $(30 \mathrm{ml})$ of the solution. These results are in good agreement with data reported in the literature for the adsorption rate of p-cresol on adsorbents of different nature [16-19]. The fact that equilibrium is attained after 24 hours in all the studied adsorbents points out the high affinity of p-cresol molecules to both the activated carbons and the carbon/diatomite composites (despite their different chemical composition). Such favored affinity of p-cresol for the solid phase -particularly for the carbonaceous adsorbents- is somewhat expected based on its low solubility in water $(1.9 \mathrm{~g} / 100 \mathrm{ml})$.

The distinct shapes of the concentration decay curves show different steps on the kinetic uptake, pointing out to the important role of the porous structure of the materials, and, more specifically, to their meso/macroporous network. The declining trend of p-cresol removal was significantly much faster for the composites than for the activated carbons used as reference materials; in contrast, the uptake in $\mathrm{KC} 3$ sample is similar to that of carbons $\mathrm{PC} 12$ and $\mathrm{C}$ (with more developed porous features). To better comprehend and analyze these differences, the kinetic data were fitted to various kinetics models; the best fitting was achieved with the pseudo-second-order kinetics [20], with correlation coefficients higher than 0.99 (Table 2). Concerning the pseudosecond order rate constant, $\mathrm{k}_{2}$, the values quoted in Table 2 follow the sequence: $\mathrm{KC} 1 \gg>$ $\mathrm{KC} 3>>\mathrm{C} \sim \mathrm{PC} 12 \sim \mathrm{AC}$. The largest value is obtained for the composite $\mathrm{KC} 1$ with the smallest carbon content, despite it showed the lowest p-cresol uptake. The other carbonaceous adsorbents present relatively close $k_{2}$ values, which are one and two orders of magnitude smaller than those of the diatomite/carbon composites. The same trends were obtained for $\mathrm{h}_{0}$ (initial adsorption rate) and $t \frac{1}{2}$ (half-life time) parameters confirming the faster adsorption rate in the hybrid adsorbents. This is of paramount importance, as it confirms that the diatomite/carbon composites are potential adsorbents for their use in environmental remediation applications, particularly when fast responses are needed. So far, carbon-based adsorbents with a macroporous structure and potential applications in environmental problems have only been obtained from nanocasting procedures [9]. In this regard, the use of the diatomite/carbon composites would avoid the high costs and risks associated to the manipulation of $\mathrm{HF}$ or concentrated $\mathrm{NaOH}$ to remove the scaffold as well as the high economic penalty associated with the use sacrificial templates.

Such extremely fast adsorption rate in the composites confirms that the accessible open pore structure of the composites provided by the diatomite (Figure 2), contributes to enhance the mass transport of the pollutant from the solution to the inner porosity of the composites (thereby 
accelerating the adsorption rate). In contrast, the rate of p-cresol removal on carbon $\mathrm{C}$, which also displays a large contribution of transport pores (Table 1), does not seem to follow the same logic (the rate constant is similar to that of microporous PC12 with a negligible mesopore volume). This indicates that the kinetics of adsorption is not exclusively governed by the porosity of the adsorbents, and that there are other factors to be considered (such as chemical composition, and/or affinity of the adsorbent/adsorbate).

\subsection{Effect of $\mathrm{pH}$}

Solution $\mathrm{pH}$ is one of the key factors that might control an adsorption process, since it influences the electrostatic interactions between the adsorbent and the adsorbate; these forces are of paramount importance in the removal of a weak electrolyte such as p-cresol. The adsorption of pcresol was studied over a $\mathrm{pH}$ range between 2-12 by adding adequate amounts of $\mathrm{NaOH}$ or $\mathrm{HCl}$ diluted solutions to the initial unbuffered solution containing the phenolic compound (Figure 4). The amount adsorbed was found to be almost constant between $\mathrm{pH}$ of 2-10 for all the adsorbents with the exception of carbon $\mathrm{C}$, and it gradually went down as the solution became more basic. These results confirm that $\mathrm{p}$-cresol is preferentially adsorbed from its neutral form $\left(\mathrm{pK}_{\mathrm{a}} \sim 10.2\right)$ even on the carbon/diatomite composites; this is in good agreement with previous studies reported for activated carbons [21]. With the exception of carbon $\mathrm{C}$, all the studied adsorbents display a somewhat basic character (Table 1). In these cases, repulsive interactions between the negatively charged adsorbents and the anionic form of $\mathrm{p}$-cresol become dominant at solution $\mathrm{pH}>\mathrm{pK}_{\mathrm{a}}$ p-cresol, thus the amount adsorbed is expected to be largely reduced. For the hydrophilic carbon $\mathrm{C}$, the retention of the aromatic compound appeared to be more $\mathrm{pH}$-dependent, as the fall in the uptake began from lower $\mathrm{pH}$ (between 4-5). This behavior is due to the different charge distribution on the surface of this carbon, which starts to be negatively charged at lower solution $\mathrm{pH}$ due to its low $\mathrm{pH}_{\mathrm{PZC}}$; consequently the repulsive interactions responsible for the fall in the amount of $\mathrm{p}$-cresol adsorbed arise from lower $\mathrm{pH}$ values.

\subsection{Equilibrium adsorption isotherms}

Figure 5 A shows the p-cresol adsorption isotherms from aqueous solution on the carbon/diatomite composites. A comparative with the isotherms corresponding to the reference activated carbons $[13,22]$ is included in Figure $5 \mathrm{~B}$. For all the adsorbents, the equilibrium adsorption isotherms display a concavity towards the abscissa axis, characteristic of L type isotherms in the Giles classification [23]. At high p-cresol equilibrium concentration in solution, 
the adsorption isotherms show a tendency to reach a plateau, indicating that adsorption proceeds through the formation of a monolayer in the range of concentration used.

From the shape of the isotherms it can also be inferred that the adsorption of p-cresol is favorable in all the studied adsorbents, and that there does not seem to be a strong competition of the solvent for the adsorption sites; this seems reasonable considering the low solubility of p-cresol in aqueous solutions (and thus its high affinity towards the solid phase).

With the exception of $\mathrm{KC} 1$, the adsorptive capacities are very similar for all the adsorbents, and at first sight it would seem that the uptake increases in adsorbents with a well-developed pore structure. Nevertheless, the low adsorption capacity displayed by carbon $\mathrm{C}$ (with the largest surface area and pore volumes) and the fact that the highest retention was obtained with sample PC12 (i.e., moderate surface area, $668 \mathrm{~m}^{2} \mathrm{~g}^{-1}$ ) indicate that this cannot be taken as a general rule.

The experimental adsorption isotherms were fitted to the classic Langmuir [24] and Freundlich models [25] (non-linear forms of the equations are displayed in Table 3). Both equations allow the evaluation of the adsorption capacity $\left(\mathrm{q}_{\mathrm{m}}\right.$ and $\left.\mathrm{K}_{\mathrm{F}}\right)$, as well as the estimation of the affinity adsorbate- adsorbent (parameters $b$ and $1 / n$ ). Table 3 compiles the main parameters obtained from the fittings to both equations, along with the correlation coefficients $\left(\mathrm{r}^{2}\right)$ and chi-square $\left(\chi^{2}\right)$ values. The excellent goodness of the fit obtained with the Langmuir equation compared to Freundlich model indicates that the former is more suitable for data interpretation of these systems. This was further corroborated by the non-linear chi-square test analysis of the data, with smaller $\chi^{2}$ values obtained for the fitting with the Langmuir equation (Table 3 ).

The obtained data corroborated the large capacity of the $\mathrm{KC} 3$ and the poor performance of activated carbon C. Moreover, the adsorption affinity of carbon $\mathrm{C}$ towards p-cresol molecules (evaluated by the $b$ parameter of Langmuir equation) is similar to that in the composite $\mathrm{KC} 3$, although both values are twice and three times smaller, respectively, than those obtained by the fitting of the isotherms corresponding to carbons AC and PC12.

To counterbalance the effect of the different porous features of these carbons, the isotherms were normalized vs the surface area of the adsorbents (Figure 5). The differences in the uptake of $p$ cresol in both composites become less remarkable after normalization, and the uptake is now slightly larger than that for PC12 carbon.

A compilation of the adsorption capacities of selected adsorbents reported in the literature [26-30] is provided in Table 4, for clarity purposes. Although it has to be considered that a straightforward comparison with data reported in the literature is a complex task due to the diversity of adsorbents and operating conditions used (i.e., initial concentration, specific surface area), our results indicate that the diatomite/carbon composites are promising adsorbents with 
great potential in the environmental remediation field. Not only their adsorption capacities are relatively high (analogous or superior to those of adsorbents with higher porous features) considering their low porous development (particularly for $\mathrm{KC} 3$ ), but the removal rate is much faster than commercial activated carbons (Figure 3 and Table 2).

The lack of a correlation between p-cresol adsorption capacities and the surface area of the adsorbents indicates that porosity is not the only parameter to be considered for the removal of p-cresol. The adsorption performance of the studied adsorbents was also examined in terms of their chemical composition. For the diatomite/carbon composites a direct correlation was found between the uptake and the carbon content, since the amount of p-cresol adsorbed increases with the carbon loading (Figure 6). However no clear trend was observed when this dependence was extended to other carbonaceous and inorganic materials (Figure 6), which carbon content has been estimated by elemental analysis. These results indicate even though there is an evident correlation for the diatomite/carbon composites, were the adsorption capacity is favored for large carbon contents, when the panel of adsorbents is extended, rather than porosity or composition themselves, a global viewpoint needs to be considered.

For the diatomite/carbon composites there seems to be a direct correlation between the uptake and the carbon content, since the amount of p-cresol adsorbed increases with the carbon loading (Figure 6). However no clear tend was observed when the dependence was extended to several carbonaceous (labels 3, 4, 5) and inorganic (labels 10, 11, 12). For instance KC3 outperforms samples labeled as 5 and 8 (Figure 6), despite its lower carbon content. The results indicate that even though there is an evident correlation for the diatomite/carbon composites, the carbon content is not the only parameter to be considered when adsorbents of varied nature are considered.

In this regard, the obtained results point out that the adsorption capacity of the polar compound seems to be linked to the hydrophobic/hydrophilic nature of the materials. Indeed, this explains the low retention ability of carbon $\mathrm{C}$-which has a hydrophilic character characterized by a large oxygen content (ca. 11 wt.\%)-, as well as the relatively high affinity of p-cresol molecules towards the diatomite/carbon composites likely due to their hydrophobic character (Table 1). Thus, it can be inferred that p-cresol adsorption is governed by the hydrophobic character of the adsorbents. This seems reasonable considering that when retention occurs in aqueous medium, the competitive adsorption of water for the active sites becomes very important in hydrophilic adsorbents [13, 31]. Although large water adsorption could be expected on the carbon/diatomite composites as a consequence of their large inorganic fraction -silica and alumina as the main constituents- , the competitive effect is minimized due to their hydrophobic nature. In the case of 
carbonaceous adsorbents, it is well known that the hydrophilic character is given by the presence of oxygen functionalities, which withdraw the $\pi$-electron density of the basal planes reducing the affinity of the carbon surface towards aromatics.

Summarizing, the diatomite/carbon composites present an adequate combination of interconnected open porous structure and hydrophobic character. Moreover, the low cost impact associated to the synthesis of these composites (related to the absence of the need to remove a sacrificial scaffold) along with their relatively large p-cresol adsorption capacities and fast adsorption rate enable their potential application in water remediation an economically feasible process.

\section{Conclusions}

The results reported in this work show that hybrid diatomite/carbon composites are adequate materials to be used in the removal of polar aromatic compounds (p-cresol) from aqueous solutions, showing adsorption capacities comparable to those of other materials reported in the literature.

The hybrid diatomite/carbon adsorbents are characterized by a hydrophobic nature and an adequate open porous network comprised of transport pores and micropores. These characteristics are partially inherited from the diatomite and the charcoal, and are a direct consequence of the synthetic route employed in the preparation, avoiding the removal of the inorganic phase as a sacrificial matrix. As a result of such combination of physicochemical features, the rate of $\mathrm{p}$ cresol removal in the diatomite/carbon composites is extremely fast. Moreover, these hybrid adsorbents present adsorption capacities similar to those of conventional adsorbents (including activated carbons and zeolites with more developed surface areas) over a wide $\mathrm{pH}$ range. This is attributed to the high affinity of p-cresol molecules towards the composites likely due to their hydrophobic character.

All these results demonstrate the suitability of these novel hybrid materials for the removal of aromatic (polar) molecules; the combination of fast adsorption and large capacities (despite a low porosity) makes them extremely attractive for their use in remediation of highly polluted streams when fast responses are needed.

\section{Acknowledgements}

$\mathrm{HH}$ grateful acknowledges the Algerian Ministry of Higher Education and Scientific Research MESRS for providing funding to support her stay in Oviedo (Spain). COA is grateful to the 
Spanish MICINN (CTM2008-01956/TECNO) and CSIC (200980I131) for financial support. The help of Ms. Ruiz in the pH study is also acknowledged.

\section{REFERENCES}

[1] K. Karlsson, M. Viklander, Polycyclic Aromatic Hydrocarbons (PAH) in Water and Sediment from Gully Pots, Water Air Soil Pollut 188 (2008) 271-282.

[2] OECD. Water Pollution by Fertilizers and Pesticides, Organisation for Economic Cooperation and Development, Paris, 1986.

[3] H. Marsh, F. Rodríguez-Reinoso. Activated carbon. Elsevier, Oxford, 2006.

[4] Roskill Information Services Ltd. The economics of activated carbon. $8^{\text {th }}$ Edition, London, 2008 .

[5] M. Tuzen, K.O. Saygi, C. Usta, M. Soylak, Pseudomonas aeruginosa immobilized multiwalled carbon nanotubes as biosorbent for heavy metal ions, Bioresour. Technol. 99 (2008) 1563-1570.

[6] M. Tuzen, K.O. Saygi, M. Soylak, Solid phase extraction of heavy metal ions in environmental samples on multiwalled carbon nanotubes, J. Hazard. Mater. 152 (2008) 632-639.

[7] H. Hadjar, B. Hamdi, M. Jaber, J. Brendlé, Z. Kessaïssia, H. Balard, J.B. Donnet, Elaboration and characterisation of new mesoporous materials from diatomite and charcoal, Microp. Mesop. Mat. 107 (2008) 219-226.

[8] H. Hadjar, B. Hamdi, Z. Kessaissia, Adsorption of heavy metal ions on composite materials prepared by modification of natural silica, Desalination 167 (2004) 165-174.

[9] D. Liu, P. Yuan, D. Tan, H. Liu, M. Fan, A. Yuan, J. Zhu, H. He, Effects of Inherent/Enhanced Solid Acidity and Morphology of Diatomite Templates on the Synthesis and Porosity of Hierarchically Porous Carbon, Langmuir 26, (2010) 18624-18627.

[10] ATSDR. Agency for Toxic Substances and Disease Registry. Toxicological Profile for Cresols. Public Health Service, U.S. Department of Health and Human Services, Atlanta, GA. 1990.

[11] US-EPA 1999. Environmental Protection Agency. Integrated Risk Information System (IRIS) on 4-methylphenol. National Center for Environmental Assessment, Office of Research and Development, Washington, DC. 1999.

[12] Directive 2000/60/EC of the European Parliament and of the Council establishing a framework for the Community action in the field of water policy", Official Journal L 327 on 22 December 2000. 
[13] C.O. Ania, B. Cabal, J.B. Parra, J.J. Pis, Importance of the hydrophobic character of activated carbons on the removal of naphthalene from the aqueous phase, Ads. Sci. Technol. 25 (2007) 155-168.

[14] S. Brunauer, L.S. Deming, W.E. Deming, E. Teller, On a theory of the van der Waals adsorption of gases, J. Am. Chem. Soc. 62 (1940) 1723-1732.

[15] F. Rouquerol, J. Rouquerol, K. Sing, Adsorption by powders \& porous solids, Academic Press, London, 1999.

[16] Md. Ahmaruzzaman, Adsorption of phenolic compounds on low-cost adsorbents: A review, Adv. Colloid Interf. Sci. 143 (2008) 48-67.

[17] P.S. Nayak, B.K. Singh, Sorption kinetics for phenol and nitro-substituted toxic phenols from aqueous solution using clay as sorbent material, Int. J. Environ. Waste Manag. 5 (2010) $286-302$.

[18] R.K. Singh, S. Kumar, S. Kumar, A. Kumar, Development of parthenium based activated carbon and its utilization for adsorptive removal of p-cresol from aqueous solution, J. Hazard. Mater. 155 (2008) 523-535.

[19] J. Huang, Treatment of phenol and p-cresol in aqueous solution by adsorption using a carbonylated hypercrosslinked polymeric adsorbent, J. Hazard. Mater. 168 (2009) 1028-1034.

[20] Y.S. Ho, Review of second-order models for adsorption systems, J. Hazard. Mater. B136 (2006) 681-689.

[21] C. Moreno-Castilla, J. Rivera-Utrilla, MV. Lopez-Ramon, F. Carrasco-Marín, Adsorption of some substituted phenols on activated carbons from a bituminous coal, Carbon 33 (1995) 845851.

[22] J.B. Parra, C.O. Ania, A. Arenillas, F. Rubiera, J.M. Palacios, J.J. Pis, Textural development and hydrogen adsorption of carbon materials from PET waste, J. Alloys Compd. 379 (2004) 280-289.

[23] C.H. Giles, T.H. MacEwan, S.N. Nakhwa, D. Smith, Studies in adsorption. Part XI. A system of classification of solution adsorption isotherms, and its use in diagnosis of adsorption mechanisms and in measurements of specific surface areas of solids, J. Chem. Soc. (OCT) (1960) 3973-3993.

[24] I. Langmuir, The adsorption of gases on plane surfaces of glass, mica and platinum. J. Am. Chem. Soc. 40 (1918) 1361-403.

[25] H.M.F. Freundlich, Over the adsorption in solution. J. Phys. Chem. 57 (1906) 385-470.

[26] R.S. Juang, F.-C. Wu, R.-L-. Tseng, Adsorption Isotherms of Phenolic Compounds from Aqueous Solutions onto Activated Carbon Fibers, J. Chem. Eng. Data 41 (1996) 487-492. 
[27] F.-Q. Liu, M-F. Xia, S.-L. Yao, A.-M. Li, H.-S. Wu, J.-L. Chen, Adsorption equilibria and kinetics for phenol and cresol onto polymeric adsorbents: Effects of adsorbents/adsorbates structure and interface, J. Hazard. Mater. 152 (2008) 715-720.

[28] S. Kumar, S.N. Upadhyay, Y.D. Upadhya, Removal of Phenols by Adsorption on Fly Ash, J. Chem. Tech. Biotechnol. 37 (1987) 281-290.

[29] S.-H. Lin, R.-C. Hsiao, R.-S. Juang, Removal of soluble organics from water by a hybrid process of clay adsorption and membrane filtration, J. Hazard. Mater. 135 (2006) 134-140.

[30] D. Bergé-Lefranc, H. Pizzala, J.L. Paillaud, O. Schäf, C. Vagner, P. Boulet, B. Kuchta, R. Denoyel, Adsorption of small uremic toxin molecules on MFI type zeolites from aqueous solution, Adsorption 14 (2008) 377-387.

[31] E.A. Muller, K.E. Gubbins, Molecular simulation study of hydrophilic and hydrophobic behavior of activated carbon surfaces, Carbon 36 (1998) 1433-1438. 
Figure 1. Nitrogen adsorption isotherms at $-196^{\circ} \mathrm{C}$ of the synthesized diatomite/carbon composites and selected activated carbons used as reference.

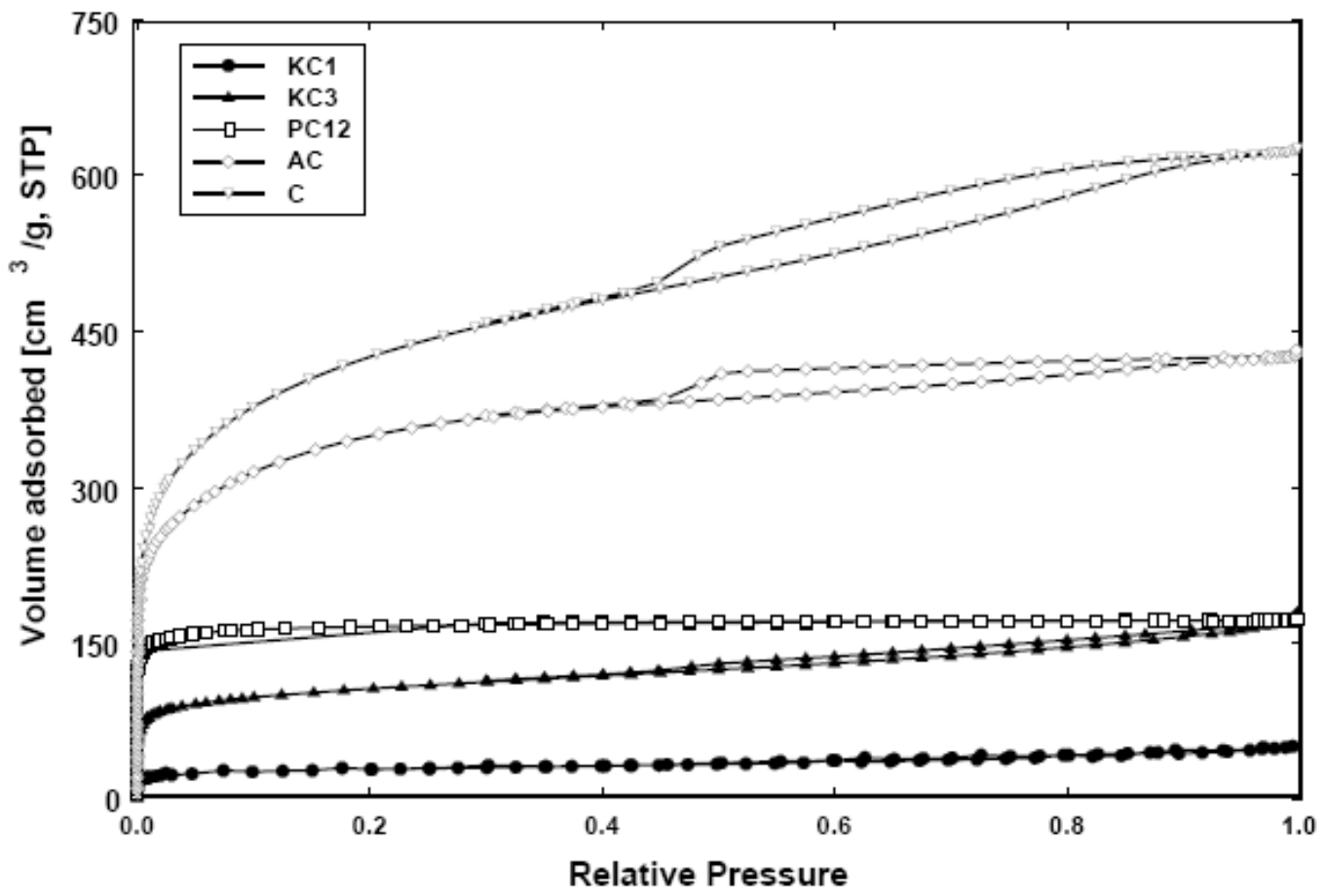


Figure 2. SEM micrographs of the as-received diatomite (KNT) and the carbon/diatomite composites ( $\mathrm{KC} 1$ and $\mathrm{KC} 3)$.

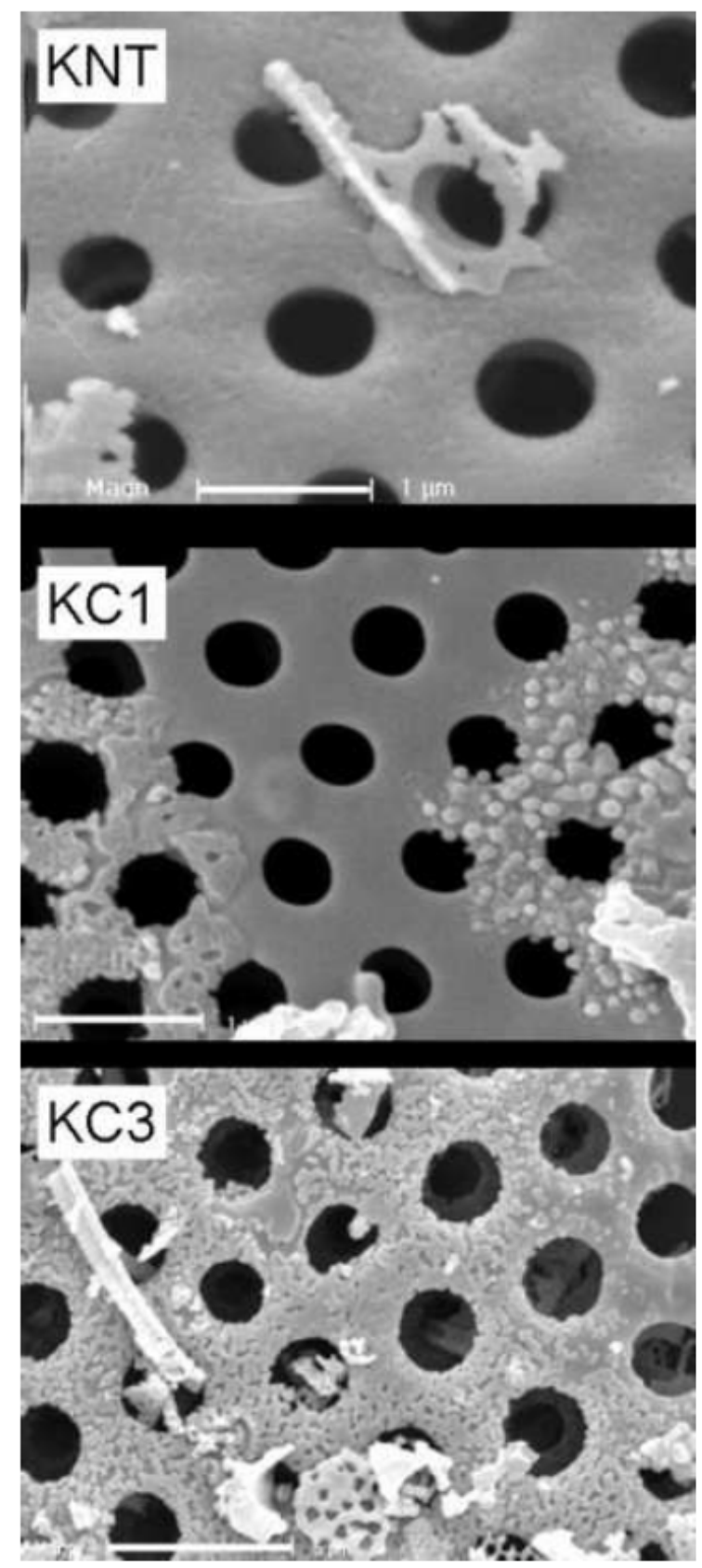


Figure 3. (A) Kinetics of p-cresol adsorption of the studied adsorbents, and (B) effect of adsorbent dosage on the removal of p-cresol from solution on $\mathrm{KC} 3$ composite. Initial concentration of p-cresol $100 \mathrm{ppm}$; volume $30 \mathrm{~mL}$.
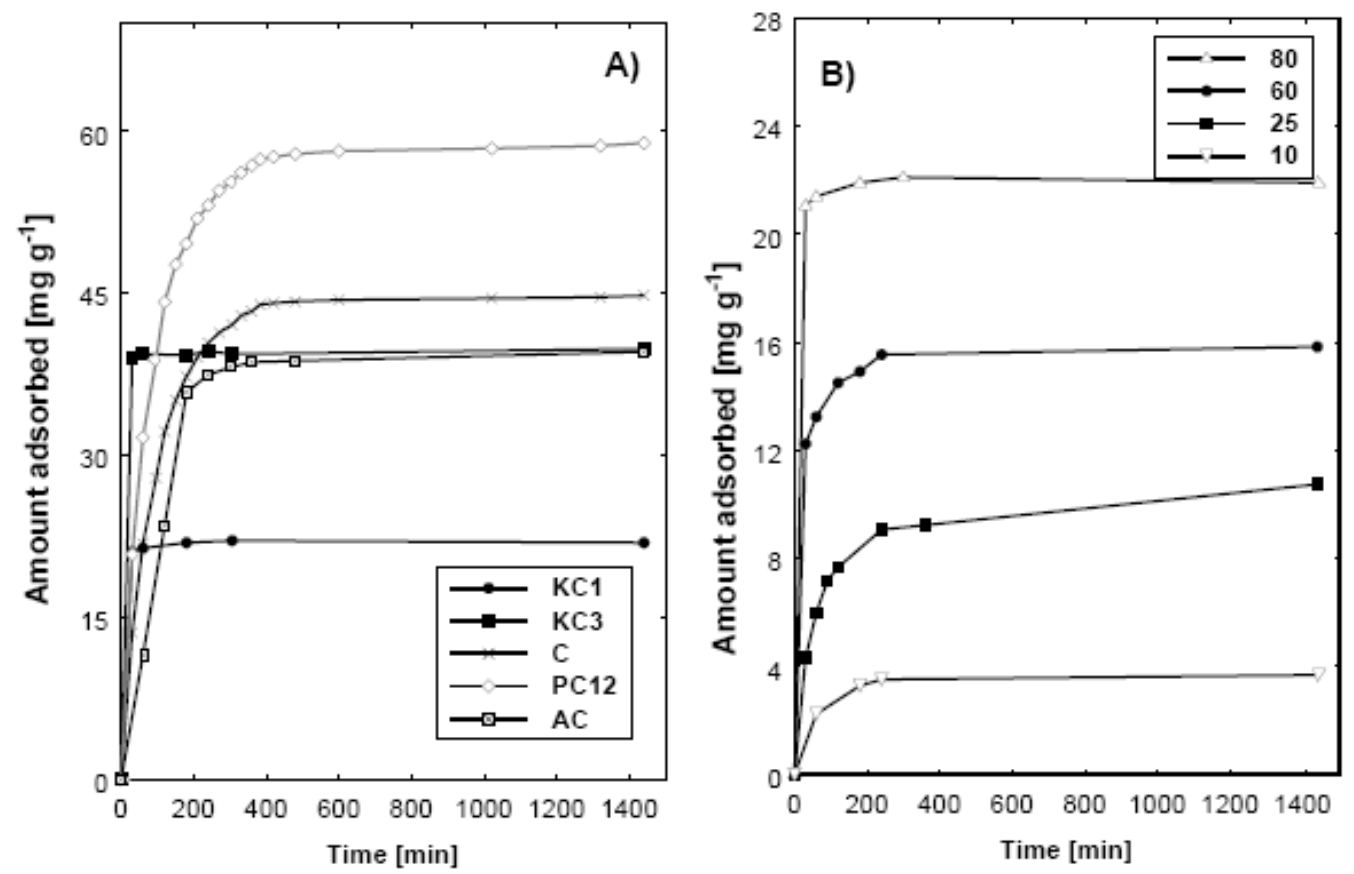
Figure 4. Effect of $\mathrm{pH}$ on the removal of p-cresol from aqueous solutions on the investigated adsorbents.

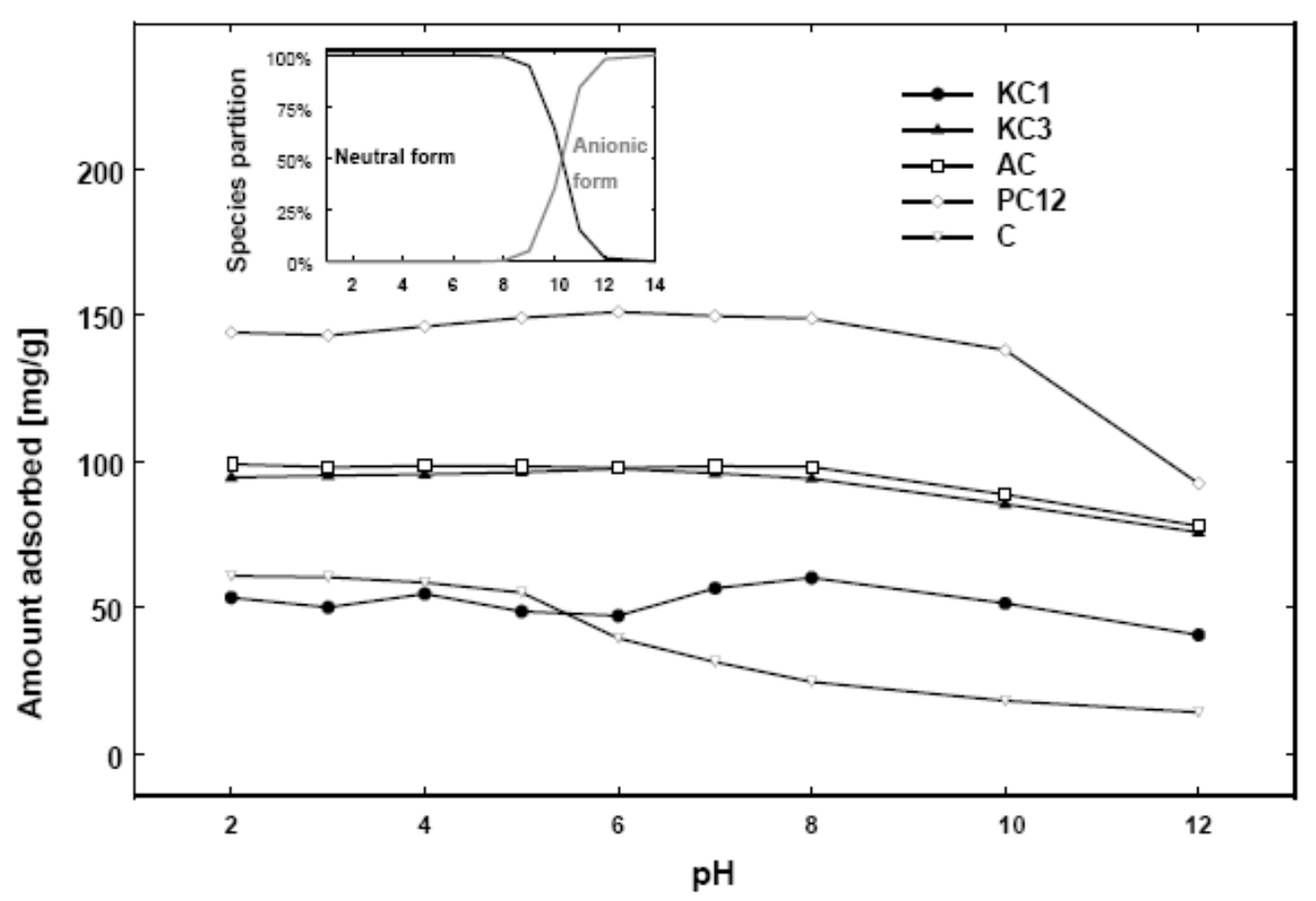


Figure 5. Equilibrium adsorption isotherms of p-cresol on the studied adsorbents (A) and normalized per unit area of the adsorbent (B). Symbols represent experimental data and lines account for the fitting to the Langmuir equation.

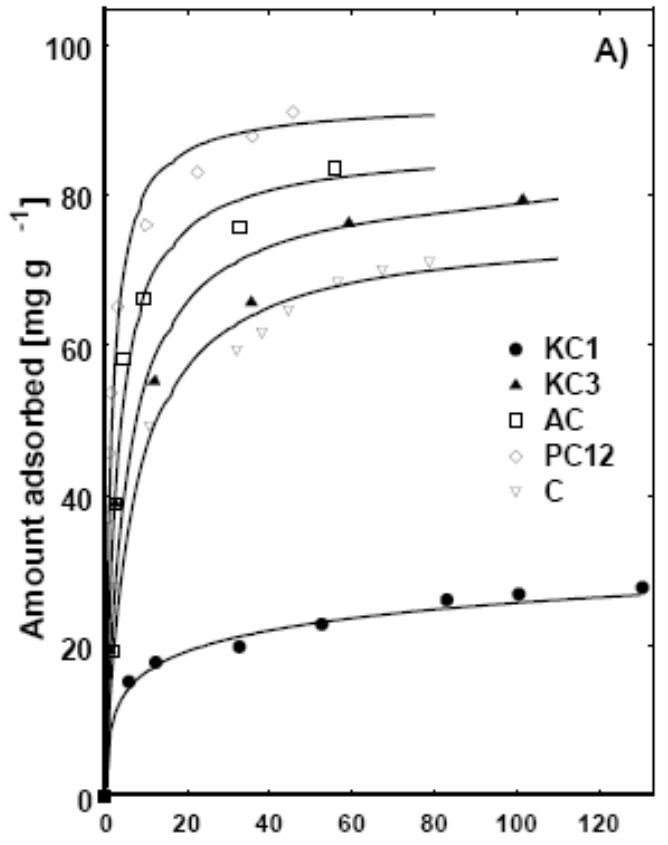

Equilibrium concentration [mg I ${ }^{-1}$ ]

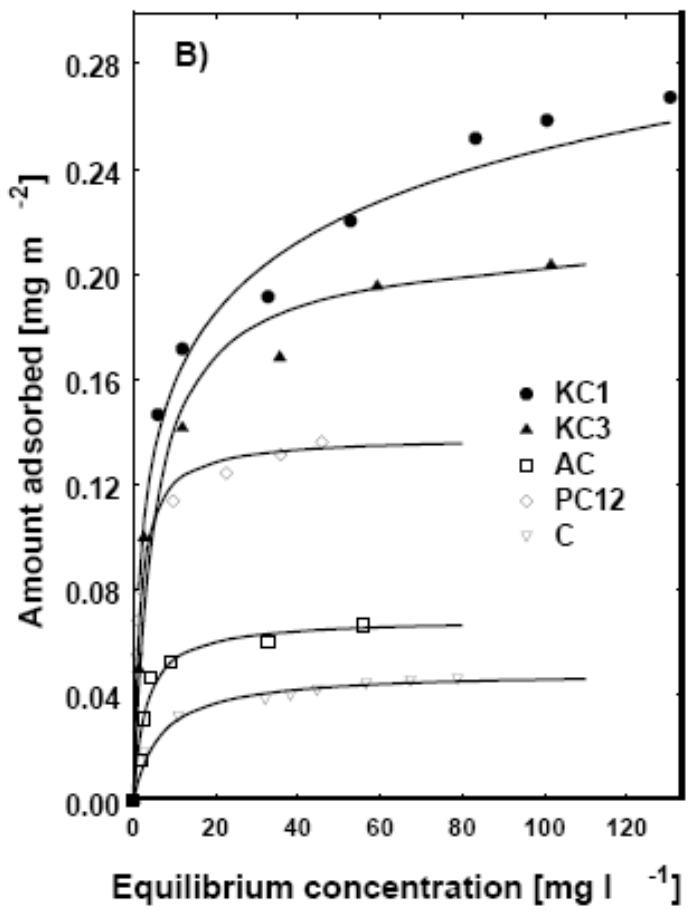


Figure 6. Dependence of the adsorption capacity vs the carbon content. Numbers account for the samples codes as indicated in Table 4.

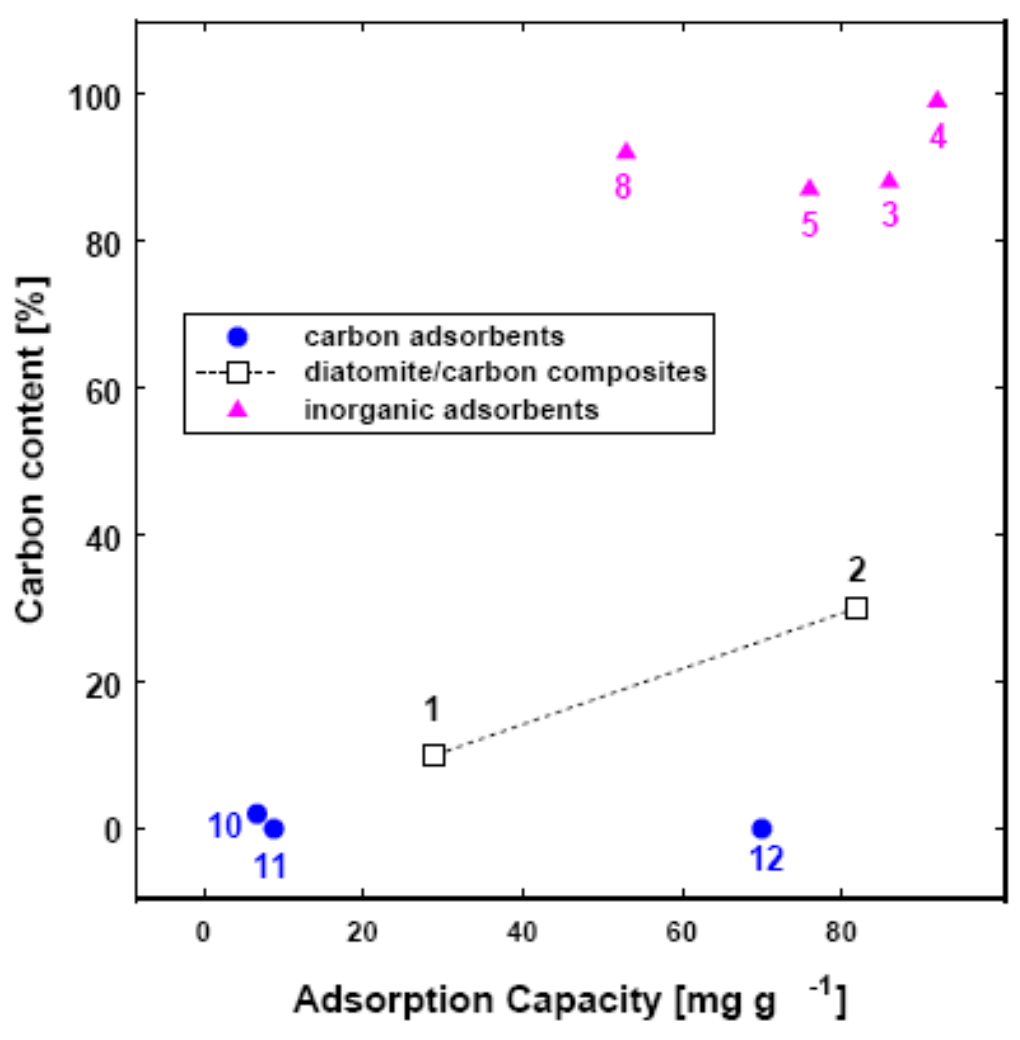


Table 1. Main chemical and textural parameters of the investigated adsorbents obtained from the $\mathrm{N}_{2}$ adsorption isotherms at $-196 \mathrm{C}$.

\begin{tabular}{|c|c|c|c|c|c|c|}
\hline & \multirow[b]{2}{*}{ Reference } & \multirow[b]{2}{*}{ pHPZC } & \multirow[b]{2}{*}{$\begin{array}{c}\text { SBET } \\
{\left[\mathrm{m}^{2} \mathbf{g}^{-1}\right]}\end{array}$} & \multirow[b]{2}{*}{$\begin{array}{l}\text { VTOTAL* } \\
{\left[\mathrm{cm}^{3} \mathbf{g}^{-1}\right]}\end{array}$} & \multicolumn{2}{|c|}{ DFT method } \\
\hline & & & & & $\begin{array}{c}\text { V MICROPORES } \\
{\left[\mathrm{cm}^{3} \mathrm{~g}^{-1}\right]}\end{array}$ & $\begin{array}{c}\text { VMESOPORES } \\
{\left[\mathrm{cm}^{3} \mathrm{~g}^{-1}\right]}\end{array}$ \\
\hline KCl & This work & 7.3 & 104 & 0.076 & 0.035 & 0.031 \\
\hline KC3 & This work & 8.5 & 390 & 0.285 & 0.112 & 0.116 \\
\hline AC & This work & 8.9 & 1255 & 0.667 & 0.380 & 0.183 \\
\hline $\mathrm{PCl} 2$ & 19 & 9.2 & 668 & 0.265 & 0.212 & 0.003 \\
\hline C & 10 & 3.1 & 1548 & 0.963 & 0.429 & 0.404 \\
\hline$\pi$ & evaluated at - & 9 relatix & ressure & & & \\
\hline
\end{tabular}


Table 2. Pseudo-second order p-cresol adsorption parameters for the studied adsorbents: $k_{2}$ is the pseudo-second order rate constant; $h_{0}$ is the initial adsorption rate; $t_{1 / 2}$ is the half-life time.

\begin{tabular}{ccccc}
\hline & $\begin{array}{c}\mathbf{k}_{2} \times 10^{4} \\
\left(\mathrm{~g} \mathrm{mg}^{-1} \text { min }^{-1}\right)\end{array}$ & $\mathbf{r}^{2}$ & $\begin{array}{c}\mathbf{t}_{1 / 2} \\
(\mathbf{m i n})\end{array}$ & $\begin{array}{c}\mathbf{h}_{0} \\
\left(\mathbf{m g ~ m i n}^{-1}\right)\end{array}$ \\
\hline KC1 & 3461 & 0.999 & 0.13 & 166 \\
KC3 & 135 & 0.999 & 1.9 & 21 \\
AC & 3.8 & 0.990 & 63 & 0.7 \\
PC12 & 4.4 & 0.999 & 37 & 1.6 \\
C & 5.1 & 0.998 & 42 & 1.1 \\
\hline
\end{tabular}


Table 3. Fitting parameters of the equilibrium adsorption isotherms to the Langmuir and Freundlich models and chi-square test analysis, $\chi^{2}$.

\begin{tabular}{|c|c|c|c|c|c|c|c|c|}
\hline & \multicolumn{4}{|c|}{ Langmuir equation } & \multicolumn{4}{|c|}{ Freundlich equation } \\
\hline & $\begin{array}{c}q_{\mathrm{m}} \\
\left(\mathrm{mg} \mathrm{g}^{-1}\right)\end{array}$ & $\left(\mathrm{dm}^{3} \mathrm{mg}^{-1}\right)$ & $r^{2}$ & $\chi^{2 *}$ & $1 / n$ & $\left.\underset{\left(\mathrm{mg}^{1-1 / n}\right.}{K_{\mathrm{F}}}\left(\mathbf{d m}^{3}\right)^{1 / n} \mathrm{~g}^{-1}\right)$ & $r^{2}$ & $\chi^{2 *}$ \\
\hline $\mathrm{KCl}$ & 29 & 0.10 & 0.993 & 0.12 & 0.20 & 11 & 0.981 & 0.03 \\
\hline KC3 & 82 & 0.20 & 0.997 & 0.67 & 0.29 & 24 & 0.889 & 2.05 \\
\hline $\mathrm{AC}$ & 86 & 0.34 & 0.998 & 1.23 & 0.34 & 25 & 0.692 & 13.1 \\
\hline $\mathrm{PCl} 2$ & 92 & 0.66 & 0.999 & 0.33 & 0.20 & 45 & 0.912 & 0.82 \\
\hline $\mathrm{C}$ & 76 & 0.15 & 0.996 & 0.04 & 0.27 & 23 & 0.967 & 0.21 \\
\hline
\end{tabular}


Table 4. Comparison of p-cresol equilibrium adsorption capacities (Langmuir fitting) for adsorbents of varied nature.

\begin{tabular}{|c|c|c|c|c|c|}
\hline & Reference & $\begin{array}{l}\mathrm{S}_{\mathrm{BET}} \\
{\left[\mathrm{m}^{2} \mathrm{~g}^{-1}\right]}\end{array}$ & $\begin{array}{c}\text { Ads. } \\
\text { Capacity } \\
{\left[\mathrm{mg} \mathrm{g}^{-1}\right]}\end{array}$ & $\begin{array}{c}\text { Codes } \\
\text { (Figure 6) }\end{array}$ & Remarks \\
\hline $\mathrm{KCl}$ & This work & 104 & 29 & 1 & \multirow{5}{*}{$\begin{array}{l}\text { p-cresol initial concentration, } \\
\text { [p-cresol]o, between } 20-120 \mathrm{ppm}\end{array}$} \\
\hline $\mathrm{KC} 3$ & This work & 390 & 82 & 2 & \\
\hline $\mathrm{AC}$ & This work & 1255 & 86 & 3 & \\
\hline $\mathrm{PCl} 2$ & 22 & 668 & 92 & 4 & \\
\hline C & 13 & 1548 & 76 & 5 & \\
\hline NDA-150 & 27 & 906 & 194 & 6 & \multirow{7}{*}{$\begin{array}{c}\text { hypercross-linked polymer } \\
\text { [p-cresol] }]_{0} \text { from } 200 \text { to } 1000 \mathrm{ppm} \\
\text { activated carbon, bituminous coal } \\
\text { [p-cresol] }]_{0} \text { up to } 150 \mathrm{ppm} \\
\text { phartenium-based activated carbon, } \\
\text { [p-cresol] }]_{0} \text { from } 100 \text { to } 1000 \mathrm{ppm} \\
\text { fly ashes } \\
\text { average adsorption capacity } \\
\text { fly ash } \\
\text { [p-cresol] }]_{0} \text { from } 50 \text { to } 600 \mathrm{ppm} \\
\text { clay } \\
\text { [o-cresol] } \\
\text { Silicalite } \\
\text { [p-cresol] }]_{0} \text { from } 50 \text { to } 600 \mathrm{ppm}\end{array}$} \\
\hline AP 2.5 & 21 & 490 & 99 & 7 & \\
\hline PAC & 18 & 260 & 63 & 8 & \\
\hline Wood FA & 16 & - & 53 & 9 & \\
\hline Fly ash & 28 & 5 & 6.7 & 10 & \\
\hline KSF & 29 & 19 & 8.8 & 11 & \\
\hline MFI & 30 & 360 & 70 & 12 & \\
\hline
\end{tabular}

